\title{
A REDE GEOGRÁFICA FORMADA PELA PRODUÇÃO E COMÉRCIO DOS CALÇADOS DE FRANCA (SP)
}

Judite de Azevedo do Carmo ${ }^{1}$

\begin{abstract}
Resumo: O objetivo principal deste texto é tratar da rede geográfica estabelecida pela produção e pelo comércio de calçados do Arranjo Produtivo Local de Franca (SP). Para tanto, apoiou-se na metodologia proposta por Corrêa (2001) para uma análise de rede geográfica. Os dados foram coletados em fontes bibliográficas e em estudo publicado pelo IEMI (2011). Identificou-se que a rede formada pela produção do calçado vai além dos limites regionais e nacionais. Quanto ao comércio, verificou-se que sua rede também ultrapassa os limites nacionais, alcançando o mercado global. No mercado interno, constatou-se que todas as regiões brasileiras são consumidoras deste produto francano; entretanto, a região sudeste se sobressai dentre as demais.
\end{abstract}

Palavras-chave: Franca; Rede Geográfica; Produção; Comércio

\section{THE GEOGRAPHICAL NETWORK OF SHOES PRODUCTION AND TRADE IN FRANCA (SP)}

\begin{abstract}
The main objective of this text is to address the geographic network established by the production and trade of footwear from the Local Productive Arrangement of Franca (SP). To this end, we relied on the methodology proposed by Corrêa (2001) for the geographic network analysis. We collected data from bibliographical sources and from a study published by IEMI (2011). The network formed by the production of the footwear was identified as extending beyond regional and national boundaries, while the trade network was found to extend beyond national boundaries, reaching the global market. Regarding the domestic market, we observed that all Brazilian regions are consumers of Franca's product; however, the southeast region stands out among the others.
\end{abstract}

Keywords: Franca; Geographic Network; Production; Trade

\section{LA RED GEOGRÁFICA FORMADA POR LA PRODUCCIÓN Y COMERCIO DE CALZADO EN FRANCA (SP)}

Resumen: El objetivo principal del presente trabajo fue analizar la red geográfica establecida a partir de la producción y el comercio de calzados en el entramado productivo local de Franca (SP). Para eso fue utilizada la metodología propuesta por Corrêa (2001) para el análisis de una red geográfica. Los datos fueron colectados en fuentes bibliográficas y en un estudio publicado por el IEMI (2011). Se constató que la red formada por la producción de calzados se extiende más allá de los límites regionales y nacionales. En cuanto al comercio, se comprobó que su red también ultrapasa los limites nacionales, alcanzando el mercado global.

\footnotetext{
${ }^{1}$ Doutora em Geografia pela Unesp, Campus de Rio Claro, professora Adjunto do Curso de Geografia da Unemat, Campus Colider. Email: juditeacarmo@gmail.com
} 
En relación con el mercado interno, fue corroborado que todas las regiones brasileñas son consumidoras de este producto francano, aunque la región sudeste sobresale entre las demás.

Palabras clave: Franca; Red geográfica; Producción; Comercio

\section{INTRODUÇÃO}

As redes geográficas constituem uma temática de interesse de várias áreas científicas e seu estudo não é recente, "tampouco a preocupação em compreender seus efeitos sobre a organização do território" (DIAS, 1995, p. 143). Entretanto é importante que se tenha claro que diversas áreas do saber vêm se apropriando do termo e apresentando interpretações diferenciadas de uma variedade de fenômenos, sejam naturais, físicos, orgânicos, dentre outros. Portanto, identificam-se autores que se dedicaram na apresentação do conceito dessas redes geográficas (CORRÊA, 2001; SANTOS, 2005, MOREIRA 2007; CORRÊA, 2011, COELHO NETO, 2013); como redes técnicas (DIAS, 1995), redes urbanas (CORRÊA, 1989; SANTOS, 1994), dentre outros.

De acordo com Corrêa (1977, p. 107), rede geográfica é "um conjunto de localizações geográficas interconectadas 'entre si’ por um certo número de ligações”. Milton Santos, em sua vasta obra, muito contribuiu com os estudos de tais redes e de acordo com ele, elas "[...] são mistas, incluem materialidade e ação". Já a rede técnica é um instrumento da produção, da circulação e da informação globalizada. Dessa forma, as redes são globais e transportam o global ao local, unindo lugares distantes numa mesma lógica de produção (SANTOS, 2005, p. 168).

São diversas as redes que se configuram na atualidade, cada uma com sua função e dentre as quais se podem citar as redes financeiras, com função de circulação rápida do capital; as redes informacionais, baseadas em novas tecnologias da informação (internet, infovias, comunicação via satélite), cuja função é a de permitir o acesso às informações em questão de instantes; redes de empresas ou empresas em rede, com a função de otimizar a atividade produtiva (PEREIRA, 2009). Portanto, cada localidade vê-se diante de ações que visam sua inserção na economia global.

Sobre os estudos desenvolvidos por geógrafos, com objetivo de analisar essa temática, Corrêa (1989, p. 10) sinaliza que estes têm sido realizados por diferentes vias, como por exemplo, a diferenciação das cidades, de acordo com suas funções; a relação entre tamanho e desenvolvimento; a hierarquia urbana, bem como as relações entre cidade e região. $\mathrm{O}$ autor coloca ainda que essas vias podem ser abordadas se interpenetrando mutuamente de diferentes modos. Contudo, atualmente, os estudos das redes geográficas aparecem renovados. 
De acordo com Dias (1995), as causas dessa renovação residem nas mudanças deste final de século, nas descobertas e nos avanços em outras áreas, bem como na própria geografia. A autora, na mesma obra, salienta que na análise das redes se faz necessário incorporar uma abordagem que não as trate de forma isolada, mas que procure suas relações, por exemplo, com a urbanização e com a divisão territorial do trabalho, complementando ainda com a afirmação de que a rede é "instrumento valioso para a compreensão da dinâmica territorial brasileira" (DIAS, 1995, p. 149).

Diante do exposto, entende-se que os estudos sobre as redes aparecem de forma renovada, porque tais redes, configuradas na atualidade, diferem-se daquelas estabelecidas em tempos mais remotos. As redes estabelecidas a priori tinham como principal objetivo a distribuição de matérias primas, objetos e pessoas e não havia uma grande preocupação com o tempo. Já as redes estabelecidas no momento atual pressupõem a emergência de uma rede de infraestrutura que dê suporte aos fluxos, sejam eles de materiais ou de informação. Por isso, torna-se imprescindível a existência de redes de transporte, de comunicação e de informação.

A evolução nos setores de transporte e de comunicação favoreceu uma maior articulação entre os diversos territórios, o que gerou uma aparente diminuição do espaço, porque houve uma aceleração na relação distância-tempo. Harvey (1993), sobre essa relação, explica que a aceleração do tempo de giro na produção envolve concomitantemente a aceleração tanto na troca como no consumo. Para tanto, os sistemas de fluxo de informações e de comunicação são aperfeiçoados, de forma a possibilitar a circulação de mercadorias em uma velocidade cada vez maior.

Segundo Coelho Neto (2013, p. 22), para a organização do espaço-tempo, “a rede é concebida como matriz técnica, remetendo-se a existência de um denso, complexo e interligado sistema de infraestruturas técnicas", as quais favorecem e "viabilizam as novas possibilidades de organização territorial das sociedades, apresenta-se como locomotiva da transformação social"'.

Os sistemas técnicos implementados no território, segundo Castells (1999), possibilitaram uma maior interligação entre os objetos no espaço, favorecendo a intensificação das ações dos agentes hegemônicos. Assim sendo, inúmeras redes são estruturadas, articulando diversas localidades e promovendo verdadeiros "espaços de fluxos".

O sistema capitalista vem ganhando complexidade com o passar dos séculos e com isso ele acaba por alterar a estrutura espacial de forma a dar condições para o seu pleno desenvolvimento. A complexidade identificada atualmente no sistema capitalista só foi possível graças à geração de novas tecnologias que proporcionaram uma reestruturação do 
processo geral de produção. Dessa forma, as empresas, sejam elas do ramo da produção ou do comércio, tenderam a criar redes que promovem maior interligação, tanto da cadeia produtiva, quanto daquela dos mercados. Essa organização em rede, de acordo com Castells (1999), foi possibilitada em razão da alta velocidade adquirida pelos meios de transporte e pela incrementação dos sistemas de informação.

A organização da produção em redes, nas quais etapas da produção são transferidas para outras indústrias, por meio da subcontratação, possibilita a expansão da produção para outras regiões, uma vez que os sistemas técnicos favorecem a interligação das unidades produtivas esparsas pelo território.

Para que a atividade produtiva continue sua expansão, faz-se necessário a existência de um mercado consumidor para seus produtos. Portanto, “entre produção e consumo capitalista se estabelece a distribuição que passa, sob a égide do capitalismo, a desempenhar papel crucial na sociedade" (CORRÊA, 2001, p.18). Na mesma obra, Corrêa expõe que por intermédio da rede hierarquizada de localidades centrais é que se realiza a articulação entre produção propriamente dita e consumo final.

O entendimento do espaço, como produto e condição para que as relações sociais se estabeleçam, pressupõe que ele é um elemento importante para o processo geral de produção e quanto a isso, Ortigoza (2001) afirma que na sociedade atual, onde a ordem é o consumo, o espaço passa a ser normatizado de forma a permitir a aceleração dos fluxos e que por meio dessa normatização é que os espaços se tornam condizentes com as novas formas de produção.

Para a plena realização do capital, por meio do processo geral de produção, há a necessidade de normas e instituições que regulem, normatizem, organizem e potencializem os fluxos pelo território. "Entretanto, o que se observa é que a circulação da mercadoria, fator fundamental para a concretização do processo produtivo, só se realiza com suporte do setor terciário, mais especificamente do comércio" (CARMO \& ORTIGOZA, 2010, p. 2684).

O comércio, da mesma forma que a produção, tem sua plena realização, na atualidade por meio de redes, quais sejam: rede de transporte, de informação, de circulação, etc. Tais redes bem elaboradas e desenvolvidas são fatores indispensáveis para a ampliação da produção e consequentemente para a elevação do lucro.

É inegável a importância das redes geográficas para a economia global; porém, elas não são apenas globais, são também locais e condições técnicas do trabalho, haja vista assegurarem a divisão do trabalho e a cooperação por meio da circulação, da distribuição e do consumo (SANTOS, 2005). 
Faz-se, então, necessária a realização de análise das redes geográficas, voltadas para o lugar, verificando as relações estabelecidas, tanto localmente, como aquelas estabelecidas em nível regional, nacional e global. Diante dessa necessidade, este artigo tem por função apresentar a análise da rede geográfica formada pela produção e pelo comércio de calçados de Franca/SP (Figura 1).

Figura 1- Localização do município de Franca -SP

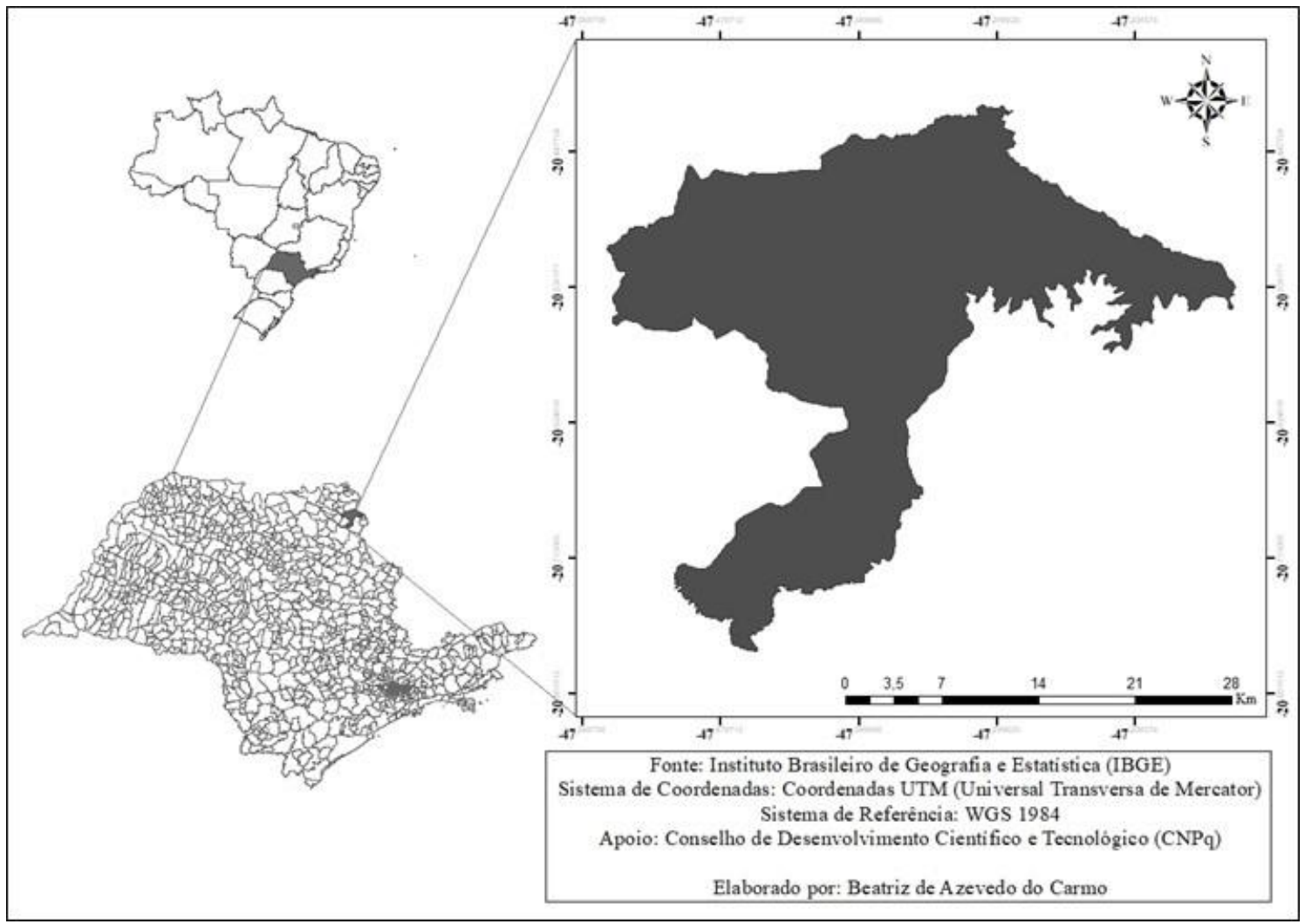

Organizado por Judite de Azevedo do Carmo

\section{Procedimentos Metodológicos}

Para a realização deste trabalho recorreu-se a uma pesquisa bibliográfica, para sua fundamentação teórica, bem como a uma coleta de dados secundários, realizada especialmente junto ao Instituto de Estudos e Marketing Industrial (IEMI), no site oficial do Sindicato da Indústria de Calçados de Franca (SINDIFRANCA), instituição de grande atuação na governança do Arranjo Produtivo Local ${ }^{2}$. Utilizou-se também, como fonte de dados, a tese de doutorado de Carmo (2012), a qual tratou dessa temática, como parte de suas reflexões sobre a relação entre indústria e comércio em APL.

\footnotetext{
${ }^{2}$ Arranjo Produtivo Local são aglomerações de empresas localizadas em um mesmo território, apresentando especialização produtiva e mantendo vínculos de articulação, interação, cooperação e aprendizagem entre si e com outros atores locais, como: governo, associações empresariais, instituições de crédito, ensino e pesquisa (Termo de referência Sebrae-2003).
} 
Para a análise da configuração da rede geográfica estabelecida pela produção e pelo comércio de calçados de Franca, adotou-se a metodologia proposta por Roberto Lobato Corrêa (2001), o qual entende que a análise deve ser realizada por meio de distintas dimensões, quais sejam: a organizacional, a temporal e a espacial.

A dimensão organizacional refere-se à configuração interna da entidade estruturada em rede, abrangendo os agentes sociais, sua origem, a natureza de seus fluxos, sua função e sua finalidade; sua existência e sua construção, sua formalização e sua organicidade. A dimensão temporal envolve a duração da rede, a velocidade com que os fluxos nela se realizam, bem como a frequência com que ela se estabelece. Finalmente, a dimensão espacial refere-se às características da rede, ou seja, seu padrão estabelecido no espaço; se ela é uma rede com centralidade geométrica ou excêntrica; ou ainda se ela se apresenta como um diferenciado arranjo espacial.

\section{Resultados e Discussão}

A atividade produtiva, organizada em rede, permite que as etapas de sua produção sejam externalizadas sob a forma de subcontratação de outras indústrias para o desenvolvimento de parte ou até mesmo de toda sua produção.

A subcontratação é muito utilizada nas indústrias calçadistas brasileiras, e em Franca não é diferente. Segundo CARMO (2012), as principais etapas da produção, realizadas por meio de subcontratação, são: modelagem, corte, acabamento; montagem, costura manual e pesponto. Este último possui o maior índice, sendo que $65,5 \%$ do total de sua produção se realizam desta forma.

A subcontratação das etapas da produção, de acordo com o IEMI (2011), é realizada quase que em sua totalidade dentro do APL de Franca e na região circunvizinha, pois 98\% dessas etapas são realizadas em Franca e em sua região e 0,10\% em outras cidades do Estado de São Paulo, sendo que somente 1,8\% ocorre em cidades de outros estados da região sudeste.

Os dados apresentados pelo IEMI (2011) indicam que os insumos e as matérias primas usadas na fabricação do calçado são, em maior parte, produzidos no próprio Arranjo Produtivo $^{3}$, ou seja, $58 \%$ deles, enquanto em outras cidades do Estado de São Paulo a

\footnotetext{
${ }^{3}$ A origem do APL de Franca tem sua explicação na localização do município em via de ligação de São Paulo com Goiás, Mato Grosso e Minas Gerais, portanto era um lugar de passagem de diversos produtos, dentre eles o couro, que juntamente com a criação de gado, disponibilizava matéria prima para a fabricação de calçado, somando-se ainda a existência de recursos naturais necessários para a preparação do couro, iniciou-se a produção de calçados já em 1932 nesta localidade, no ano de 1940 surgem outras atividades ligadas à indústria calçadista,
} 
produção é de $20 \%$ e em outros Estados temos uma taxa de $21 \%$; já em outros países essa taxa é de1,2\%. Portanto, não há uma grande dependência desse setor em relação a outros municípios do Estado de São Paulo, nem tampouco de outros Estados.

A partir da análise dos dados levantados no IEMI (2011), há o entendimento de que todas as etapas de produção dos calçados do APL são realizadas quase que em sua totalidade no município de Franca e em sua região; portanto é possível concluir que aí se encontra toda a cadeia produtiva do couro. Entretanto, a rede formada pela produção do APL ultrapassa os limites do município, chegando até a escala global, haja vista uma porcentagem de insumos e de matérias primas consumidas ser originada em outros municípios do Estado de São Paulo ou em outros Estados do Brasil, sendo que um mínimo ainda vem de outros países.

No que se refere à rede formada pelo comércio de calçados fabricados em Franca é possível inferir que esta ultrapassa os limites municipais, regionais e nacionais, atingindo o mercado global, uma vez que os principais canais de escoamento da produção de calçados de Franca, de acordo com o CARMO (2012), são: varejos especializados (75,1\%), varejo nãoespecializado $(9,5 \%)$, comércio atacadista $(0,3 \%)$, lojas de pronta entrega $(1,7 \%)$, exportação $(12 \%)$; e outros canais $(1,3 \%)$.

Como pôde ser observado, dentre os diversos canais de distribuição utilizados pelas indústrias do APL de Franca, os varejos especializados se sobressaem. Isso acontece porque os industriais preferem colocar seus produtos em lojas próprias, vendendo no varejo ou mantendo representantes que façam contatos comerciais com os lojistas, responsáveis pelas lojas de varejo especializado, ou ainda manter as lojas franquiadas, vendendo somente suas marcas.

Os outros tipos de comércio realizados pelas indústrias calçadistas de Franca, apresentados pelo IEMI (2011), são a venda por catálogo, por internet e de porta em porta; e estes, em 2009, perfizeram um total de 1,3\% em relação ao total de escoamento da produção.

A exportação também é um canal de escoamento muito utilizado pelo APL; cerca de 12\% da produção em 2009 se destinaram a outros países. De acordo com IEMI (2011), os principais países importadores de calçados de Franca, por ordem de participação nas exportações realizadas, são: Estados Unidos (47, 82\%), Espanha (10,12\%), França (9,60\%), Arábia Saudita (7,56\%), Rússia (5,06\%), Reino Unido (3,68\%), Equador (2,21\%), Paraguai $(1,62 \%)$ e Venezuela $(1,61 \%)$.

formando-se então o Arranjo Produtivo Local, o qual veio a se consolidar e apresentar grande expansão a partir de 1970; e, na atualidade seus produtos atingem o mercado nacional e global (CARMO 2012). 
As exportações de calçados do APL de Franca são realizadas individualmente pelas indústrias, tendo como principais executores o agente de exportação e o representante. 61,3\% das indústrias utilizam marcas próprias e apenas metade delas usam marcas dos clientes externos (IEMI, 2011). Contudo, o volume de calçado exportado com marca própria e marca do cliente é bem equiparado. Os Estados Unidos são o principal mercado consumidor externo dos calçados de Franca.

Como pode ser verificado pelos dados do Instituto de Estudos e Marketing Industrial (2011), o APL de Franca possui importante participação nas exportações brasileiras de calçados, porém as vendas no mercado interno são superiores, sendo que em 2010, de acordo com a resenha estatística elaborada pelo Sindicato da Indústria de Calçados de Franca (2011), $87 \%$ da produção teve como principal destino geográfico o mercado interno. Isto ocorre porque os industriais acreditam que, em época de crise, tal mercado é mais estável e, portanto, eles não deixam de investir nele.

No mercado interno, os calçados de Franca atingem todas as regiões brasileiras; porém, a maior porcentagem, ou seja, $65 \%$ da produção destinada a esse mercado tem como destino final a região sudeste; o restante, 35\%, dirige-se a outros Estados brasileiros (IEMI, 2011). Verifica-se então que, apesar dos calçados francanos chegarem a todas as regiões do Brasil, a região sudeste é o seu principal mercado consumidor. Nesse ponto, é interessante ressaltar que para a região de Franca somente são destinados $9 \%$ da produção, evidenciandose que as indústrias de Franca estão mais direcionadas ao mercado nacional e ao internacional.

Sobre o consumo dos calçados de Franca, Carmo (2012) identificou que ele é maior nas populações pertencentes aos grupos $\mathrm{B}$ e C. Poucas pessoas do grupo $\mathrm{D}$ e $\mathrm{E}^{4}$ consomem os produtos do APL. Dessa forma, é possível o entendimento de que o produtor procura desenvolver seus produtos com uma qualidade superior para que possa ser adquirido pelo grupo de população que possui poder aquisitivo mais elevado, embora ainda não consiga atingir satisfatoriamente o grupo A, ficando este em terceira posição quanto ao consumo dos calçados francanos.

A partir da análise dos dados levantados é possível apresentar as configurações da rede geográfica do APL de Franca no que concerne à produção e ao comércio de calçados, conforme pode ser observado no quadro 1.

\footnotetext{
${ }^{4}$ De acordo com o IBGE a classificação da população em classes sociais segue basicamente o critério:

Classe A: Rendimento mensal acima de 30 salários mínimos; Classe B: De 15 a 30 salários mínimos; Classe C: De 6 a 15 salários mínimos; Classe D: De 2 a 6 salários mínimos; Classe E: Até 2 salários mínimos.
} 
Quadro 1- Configuração da Rede Geográfica do APL de Franca (SP)

\begin{tabular}{|c|c|c|c|}
\hline \multicolumn{2}{|c|}{ Rede analisada segundo: } & Especificação & Exemplos \\
\hline \multirow{11}{*}{$\begin{array}{l}\text { Dimensão } \\
\text { Organiza- } \\
\text { cional }\end{array}$} & Agentes & $\begin{array}{l}\text { Indústria, } \\
\text { comércio, } \\
\text { serviços } \\
\text { instituição } \\
\text { apoio }\end{array}$ & $\begin{array}{l}\text { Unidades produtivas e fornecedoras de insumos e matérias } \\
\text { primas, unidades de vendas no mercado interno e externo e } \\
\text { escritório de agentes de comercialização, instituição de apoio } \\
\text { (estab. de ensino, sindicato, prefeitura, SEBRAE,etc.) }\end{array}$ \\
\hline & Origem & $\begin{array}{l}\text { Espontânea } \\
\text { planejada }\end{array}$ & $\begin{array}{l}\text { No início foi espontânea, mas conforme foi expandindo a } \\
\text { atividade produtiva no município ela tornou-se planejada. }\end{array}$ \\
\hline & \multirow{2}{*}{$\begin{array}{l}\text { Natureza } \\
\text { dos fluxos }\end{array}$} & Mercadorias & Matérias primas, insumos e produtos acabados. \\
\hline & & Informações & $\begin{array}{l}\text { Entre as empresas sobre a produção e o comércio, entre os } \\
\text { empresários e os agentes de governança. }\end{array}$ \\
\hline & Função & $\begin{array}{l}\text { Produção } \\
\text { comércio }\end{array}$ & $\begin{array}{l}\text { Distribuição da atividade produtiva e distribuição de produtos } \\
\text { acabados. }\end{array}$ \\
\hline & Finalidade & Acumulação & $\begin{array}{l}\text { Distribuição da atividade produtiva de forma a reduzir custos e } \\
\text { aumentar a produção e o lucro; distribuição dos produtos } \\
\text { acabados de forma a obter melhor inserção nos mercados. }\end{array}$ \\
\hline & \multirow[t]{2}{*}{ Existência } & Real & $\begin{array}{l}\text { Utilização de sistemas viários para distribuição da atividade } \\
\text { produtiva e dos produtos acabados. }\end{array}$ \\
\hline & & Virtual & $\begin{array}{l}\text { Utilização de sistemas de comunicação como internet } \mathrm{e} \\
\text { telefone. }\end{array}$ \\
\hline & \multirow[t]{2}{*}{ Construção } & Material & $\begin{array}{l}\text { Pontos fixos (e fornecedoras de insumos e matéria prima, } \\
\text { empresas produtoras, empresas comercializadoras e escritórios } \\
\text { de agentes de comércio interno e externo). }\end{array}$ \\
\hline & & Imaterial & Fluxos de dados e informações entre os integrantes da rede \\
\hline & Formalização & Formal & $\begin{array}{l}\text { Contratos entre as empresas de fabricação de calçados e as } \\
\text { empresas fornecedoras e prestadoras de serviços e a realização } \\
\text { de pedidos pelas empresas comercializadoras e agentes de } \\
\text { comércio. }\end{array}$ \\
\hline $\begin{array}{l}\text { Dimensão } \\
\text { Organiza- } \\
\text { cional }\end{array}$ & Organicidade & $\begin{array}{l}\text { Comple- } \\
\text { mentaridade }\end{array}$ & $\begin{array}{l}\text { Entre as unidades de produção de calçados e os demais } \\
\text { integrantes da rede. }\end{array}$ \\
\hline \multirow{6}{*}{$\begin{array}{l}\text { Dimensão } \\
\text { Temporal }\end{array}$} & Duração & Longa & $\begin{array}{l}\text { Entre as unidades envolvidas no processo de produção do } \\
\text { calçado e as unidades comercializadoras e agentes de comércio. }\end{array}$ \\
\hline & \multirow{3}{*}{$\begin{array}{l}\text { Velocidade } \\
\text { dos fluxos }\end{array}$} & Lenta & $\begin{array}{l}\text { Distribuição de matérias primas, insumos e produtos acabados } \\
\text { por meio de vias terrestres. }\end{array}$ \\
\hline & & Rápida & Distribuição da produção para o exterior por meio de via aérea. \\
\hline & & $\begin{array}{l}\text { Rápida a } \\
\text { Instantânea }\end{array}$ & $\begin{array}{l}\text { Informação entre os agentes envolvidos na produção e } \\
\text { comercialização dos calçados por meio de via rádio, cabo de } \\
\text { fibra óptica. }\end{array}$ \\
\hline & \multirow[t]{2}{*}{ Frequência } & Permanente & $\begin{array}{l}\text { Entre as empresas envolvidas na produção e comercialização } \\
\text { dos calçados. }\end{array}$ \\
\hline & & Periódica & $\begin{array}{l}\text { Quando da realização das feiras buscando a inserção dos } \\
\text { calçados em novos mercados. }\end{array}$ \\
\hline \multirow{7}{*}{$\begin{array}{l}\text { Dimensão } \\
\text { Espacial }\end{array}$} & \multirow{4}{*}{ Escala } & Local & $\begin{array}{l}\text { Entre as unidades produtivas, fornecedoras e subcontratadas e } \\
\text { os estabelecimentos comerciais no município de Franca. }\end{array}$ \\
\hline & & Regional & $\begin{array}{l}\text { Entre as unidades produtivas locais e as da região, e entre os } \\
\text { fornecedores e unidades de comercialização da região de } \\
\text { Franca. }\end{array}$ \\
\hline & & Nacional & $\begin{array}{l}\text { Entre as unidades produtivas, fornecedores de nível nacional, } \\
\text { assim como com os agentes de mercado do Brasil e as unidades } \\
\text { de comercialização. }\end{array}$ \\
\hline & & Global & $\begin{array}{l}\text { Entre as unidades produtivas, fornecedoras, estabelecimentos } \\
\text { comerciais e os agentes de mercado externo. }\end{array}$ \\
\hline & $\begin{array}{l}\text { Forma } \\
\text { Espacial }\end{array}$ & Circuito & $\begin{array}{l}\text { Pontos interligados no município, na região e no território } \\
\text { nacional e mundial por onde fluem os insumos, as matérias- } \\
\text { primas e os produtos acabados por meio de vias terrestres e } \\
\text { marítimas. }\end{array}$ \\
\hline & \multirow{2}{*}{ Conexão } & Interna & $\begin{array}{l}\text { Forte conexão entre as unidades envolvidas na produção dos } \\
\text { calçados em nível local, regional e nacional. }\end{array}$ \\
\hline & & Externa & $\begin{array}{l}\text { Forte, as vezes instável entre unidades produtivas e unidades } \\
\text { de comercialização numa escala territorial mais abrangente. }\end{array}$ \\
\hline
\end{tabular}

Fonte: CARMO (2012) 
Em observação ao quadro 1 é possível a identificação de que a rede geográfica do APL de Franca possui uma existência real por meio da circulação de matérias primas e dos produtos acabados que utilizam principalmente os sistemas rodoviários; porém, possui também uma existência virtual, no momento em que há a utilização de meios de comunicação como a internet, telefones para troca de informações e realização dos pedidos.

A origem da rede deu-se de forma espontânea, mas no decorrer da expansão da atividade, ela se tornou planejada, principalmente com o intuito de obter um maior alcance territorial e maior ampliação dos lucros.

A rede formada envolve agentes como representantes de indústrias, do comércio, dos serviços e de instituições de apoio. Os fluxos observados na rede são imateriais como as informações, mas também são materiais como as mercadorias.

A construção da rede geográfica é material, pois se pode observar em campo a existência de seus pontos fixos que são: as unidades produtivas, os estabelecimentos comerciais, as empresas de prestação de serviço, os escritórios e as instituições de apoio. Entretanto, ela também é imaterial, quando se observa os fluxos de informações e de comunicação entre os pontos fixos.

A formalização da rede ocorre por meio de contratos estabelecidos entre as unidades produtivas e as unidades fornecedoras de insumos e de matéria prima, bem como por intermédio de encomendas para produção.

A forma como a rede é organizada proporciona uma complementaridade entre os agentes envolvidos, o que lhes confere maior eficácia no processo de acumulação de capital, sendo esta a sua principal finalidade.

Os fluxos da rede apresentam velocidade desde lenta até a instantânea. A primeira ocorre nos fluxos de distribuição de insumos, de matérias primas e de produtos acabados, por utilizar as rodovias, especificamente no território nacional, e por vias marítimas, quando se trata do mercado externo, e a outra quando utiliza internet e telefones para os fluxos de informação e de comunicação.

A rede possui uma duração que vai desde a longa até a rápida e instantânea. Possui duração longa por meio das relações de produção estabelecidas entre as indústrias contratantes e as subcontratadas, bem como entre as indústrias e os estabelecimentos comerciais. A duração da rede pode ser considerada de rápida a instantânea quando se verifica os fluxos de informação entre os agentes, o que ocorre por intermédio de via rádio, cabo de fibra óptica, etc. 
O estabelecimento da rede é permanente entre as unidades produtivas e as fornecedoras de insumos e de matéria prima; entretanto, possui um estabelecimento periódico durante a realização de feiras do setor calçadista, dos cursos de capacitação, estes oferecidos pelas instituições de apoio e quando da contratação de serviços temporários.

A forma espacial apresentada pela rede é de circuito, uma vez que há uma interligação de pontos, tanto no município de Franca, quanto em sua região; já no território nacional e mundial, a conexão interna entre as unidades produtivas é bastante forte. No que se refere à conexão externa, ela também é forte; no entanto, em alguns momentos, mostra-se instável entre as unidades produtivas e as unidades de comercialização, tanto em escala local quanto na territorial mais abrangente.

Para finalizar a análise é importante apontar que a rede geográfica do APL é realizada em várias escalas espaciais, que vão desde a local até a internacional. Em escala local, ela se manifesta com maior expressão entre as unidades produtivas e as fornecedoras de insumos, de matérias primas, bem como entre as unidades de comercialização próprias e as instituições de apoio. Já com menor expressão, tem-se a relação entre as unidades produtivas e as unidades de comercialização independentes.

Em escala regional, a rede é formada entre as unidades produtivas locais e as da região, bem como entre os fornecedores, assim como entre algumas unidades de comercialização. Em escala nacional, ela se estabelece com menor intensidade entre as unidades produtivas e os fornecedores; porém, há uma maior intensidade em nível nacional entre as unidades produtivas e as unidades de comercialização própria; já com as unidades de comercialização independentes a intensidade da rede é menor.

Em escala global, o estabelecimento da rede geográfica apresenta intensidade reduzida entre as unidades produtivas e as fornecedoras de insumos e de matérias primas. Ainda nesta escala registra-se a intensidade do estabelecimento da rede um pouco mais elevada entre as unidades produtivas e os agentes de mercado externo, assim como entre seus representantes comerciais.

Esta é a configuração da rede geográfica formada pela produção e pelo comércio de calçados do Arranjo Produtivo Local de Franca (SP), identificada por meio da aplicação da metodologia proposta por Corrêa (2001). 


\section{Considerações Finais}

$\mathrm{Na}$ atualidade é considerável o aumento das novas formas de organização da produção, com destaque para a implantação de unidades produtivas flexíveis. Essas novas formas de organização só foram possíveis graças ao uso de tecnologias aplicadas à informação, que favoreceram a formação das redes geográficas no âmbito da produção e do comércio. A produção e o comércio, organizados em rede, são conteúdos que devem ser considerados para que se possa compreender a sociedade atual e seu espaço.

O trabalho desenvolvido com a adoção da proposta de Corrêa (2001) para a análise da rede geográfica do Arranjo Produtivo Local de Franca foi de grande contribuição, pois por meio desse procedimento foi possível desvendar e caracterizar a rede formada pela produção e pelo comércio dos calçados do APL, bem como ressaltar suas diferentes territorialidades, as quais se apresentam de acordo com os tipos de relações estabelecidas entre os agentes por ela envolvidos.

É importante ainda especificar que a aplicação da metodologia proposta por Corrêa (2001) se mostrou extremamente eficaz, haja vista por seu intermédio ter sido possível realizar a síntese e a visualização da abrangência da rede geográfica formada pelo APL de calçados masculinos de Franca (SP).

A apresentação da configuração da rede geográfica estabelecida pela produção e pelo comércio dos calçados francanos pode servir de instrumento às instituições que atuam na governança do APL, pois por seu intermédio pode se identificar os pontos fracos e os fortes dessa rede.

\section{Referencias Bibliográficas}

CARMO, J. A.; ORTIGOZA, S.A.G. O Estudo do Comércio no Contexto da Dinâmica dos Arranjos Produtivos Locais. In: I CONGRESSO BRASILEIRO DE ORGANIZAÇÃO DO ESPAÇO E X SEMINÁRIO DE PÓS-GRADUAÇÃO EM GEOGRAFIA. Anais...Rio Claro: UNESP, 2010. p. 2672- 2688. Disponível em: 〈http://www.cboe.tk/>. Acesso em 05 Jun. 2014.

CARMO, J. A. O Comércio no Arranjo Produtivo Local Calçadista de Franca (SP). 2012. 220 f. Tese (Doutorado em Geografia) - Instituto de Geociências e Ciências Exatas, Universidade Estadual Paulista "Júlio de Mesquita Filho", Rio Claro, 2012.

CASTELLS, M. A Era da Informação: Economia, Solidariedade e Cultura. A Sociedade em Rede. 2 ed. Tradução de Roneide Venâncio Majer e Klauss Brandini Gerhardt. São Paulo: Paz e Terra. Vol. 1, 1999.

COELHO NETO, A. S. Redes e territórios. Mercator. V. 12, n. 28. Fortaleza, maio/ago/2013. 19-34. p. Disponível em: <http://www.mercator.ufc.br/index.php/mercator/article/view/738/483> Acesso em: 05 Jun. 2014. 
CORRÊA, R. L. Status Sócio-Econômico e Centralidade: Uma Interpretação. Geografia, V. 2, N. 3, 1977. p. 51-59.

CORRÊA, R. L. A Rede Urbana. São Paulo: Ática, 1989.

CORRÊA, R. L. Trajetórias Geográficas. 2a ${ }^{a}$ ed. Rio de Janeiro: Bertrand Brasil, 2001.

CORRÊA, R. L. Redes Geográficas: Reflexões Sobre um Tema Persistente. Cidades, V. 9 N. 16, s/ed. 2011. Disponível em :

<http://revista.fct.unesp.br/index.php/revistacidades/article/viewFile/2378/2122> Acesso em: 20 Mai. 2012.

DIAS, L. C. Redes: Emergência e Organização. In: CASTRO, I. et al (orgs).Geografia, Conceitos e Temas. São Paulo: Bertrand Brasil, 1995.

HARVEY, D. Condição Pós-Moderna. Tradução de Adail Ubirajara Sobral e Maria Stela Gonçalves. Rio de Janeiro: Loyola, 1993.

IEMI. Instituto de Estudos e Marketing Industrial. Estudo sobre o setor de calçados de Franca e região. Fev/2011. Disponível em:

<http://www.sindifranca.org.br/edicoes_revista/marco2011/catalogo.html>. Acesso em diversas datas.

MOREIRA, R. Da região à rede e ao lugar: a nova territorialidade e o novo olhar geográfico sobre o mundo. Espaço, tempo e crítica. V. 1, N. 3, 2007. p. 65-70. Disponível em:

<http://www.uff.br/etc/UPLOADs/etc\%202007_1_3.pdf> Acesso em: 20 Mai. 2012.

ORTIGOZA, S. A. G. O Tempo e o Espaço da Alimentação no centro da Metrópole Paulista. 2001. 196 f. Tese (Doutorado em Geografia) - Instituto de Geociências e Ciências Exatas, Universidade Estadual Paulista "Júlio de Mesquita Filho", Rio Claro, 2001.

PEREIRA, MIRLEI. F. V. Redes, sistemas de transportes e as novas dinâmicas do território no período atual: notas sobre o caso brasileiro. Sociedade \& Natureza, Uberlândia, V. 1, N. 21, 2009. p. 121-129.

Disponível em: <http://www.scielo.br/pdf/sn/v21n1/v21n1a08.pdf> Acesso em: 20 Mai.2012. SANTOS, M. A urbanização brasileira. 2. Ed. São Paulo: Hucitec, 1994.

SANTOS, M. Da totalidade ao lugar. São Paulo: Edusp, 2005.

SEBRAE. Termos de Referência para atuação do Sistema SEBRAE em Arranjos Produtivos Locais. Brasília: SEBRAE, 2003. p. 17 (série documentos).Curitiba, Setembro de 2006.

SINDIFRANCA. Sindicato da Indústria de Calçados de Franca. Resenha Estatística, abril/2011. Disponível em: <http://www.sindifranca.org.br/downloads.asp>. Acesso em: 12 Nov.2011.

Recebido em 16 de junho de 2015.

Aceito em 24 de maio de 2018. 